\title{
USING REVENUE SHARING TO IMPLEMENT FLEXIBLE PRICES: EVIDENCE FROM MOVIE EXHIBITION CONTRACTS*
}

\author{
RICARD GIL ${ }^{\dagger}$ \\ Francine LAFONTAINE
}

\begin{abstract}
Movie exhibition contracts entail revenue-sharing terms that go down with weeks since release. We develop a simple model to show how the form of these contracts can be explained by the distributors' desire to set flexible prices. We then use detailed data on theater-movie contracts in Spain, where we exploit the information available at the time of contracting for movies previously released in the U.S., and other movie and theater characteristics, to show how the implications of our flexible pricing argument are supported in the data, and differentiate our explanation from prior, more standard risk-sharing and moral-hazard explanations.
\end{abstract}

\section{INTRODUCTION}

THE LITERATURE ON SHARE CONTRACTS IN ECONOMICS has evolved in important ways since its early days, when authors decried the existence of such backward institutions as sharecropping. In a well-functioning market, they argued, sharing would be replaced by single price contracts yielding firstbest efforts and outcomes (e.g., see Binswanger and Rosenzweig [1984] p. 16). The persistence of various forms of sharing in agriculture but also in other industries in developed economies led authors to reconsider the ques-

\footnotetext{
*We sincerely thank the several company officials who gave us access to the data and shared their knowledge of the institutional norms in the Spanish movie industry. We also thank The Editor and two anonymous referees for their very helpful comments, as well as participants at the American Law and Economics Association Meetings and the NBER Summer IO conference, and seminar participants at Harvard University, MIT, the Oregon State University, UC San Diego, the Carlos III University of Madrid, the University of Florida, the University of Oviedo, l'Universite de Paris X, the University of Virginia and Western Michigan University for their comments and suggestions. Finally, we thank Robert Picard for his generous assistance, and our respective institutions for support. The usual disclaimer applies.

${ }^{\dagger}$ Authors’ affiliations: Carey Business School, Johns Hopkins University, 100 International Drive, Baltimore, Maryland, U.S.A. e-mail: ricard.gil@jhu.edu.

${ }^{+}$Ross School of Business, University of Michigan, 701 Tappan Street, Ann Arbor, Michigan, 48109, U.S.A.

e-mail:laf@umich.edu.
} 
tion of why such contracts exist, and arrive at a new consensus whereby they are seen as solutions to risk-sharing and incentive problems. ${ }^{1}$

In this paper, we consider a different explanation that we believe accounts for the ubiquity of share contracts in the movie distribution industry, the focus of our empirical analyses, but also in other contexts such as retail real estate leasing and technology licensing contracts. In particular, we argue that it is the uncertainty about the value of any given movie in any given market at the time of contracting that leads distributors to rely on revenue-sharing contracts. This explanation emphasizes the theaters' participation constraint, which translates into their incentive to show the movie in a given week and/or renegotiate terms, rather than marginal effort provision, as the major motivation behind revenue sharing. ${ }^{2}$

Our simple, flexible pricing model yields a number of predictions that we test using data on the Spanish distribution industry. In particular, it implies that distributor shares will be higher for movies that are expected to yield higher box-office revenues. We exploit the information available at the time of contracting about the success of movies previously released in the U.S. to test this hypothesis. Second, because of the need to keep satisfying the exhibitor's participation constraint week after week, as box office revenues decrease with weeks since release, the share to the distributor should decrease from week to week as well. As ours is a pricing argument, the model also emphasizes how higher values of alternative opportunities for the exhibitor, higher exhibitor operational costs, and higher exhibitor market shares should lead to lower distributor shares. We find support for these predictions in our data, in addition to presenting evidence against the traditional risk-sharing and marginal incentive argument for the form of movie distribution contracts. On the latter, for example, we present evidence that the contract terms of movies with below-expectations results are more likely to be renegotiated after the fact. In other words, exhibitors are protected from bad outcomes via renegotiation, thereby eliminating the need to insure them via revenue sharing. We conclude that flexible pricing is a much more promising explanation for the data patterns, and thus for the use of share contracts in this, and we believe other markets as well.

The paper is organized as follows. In the next section, we describe the institutional features of our empirical setting, the distributor/theater relations in the motion picture industry in Spain. Next we develop a simple

\footnotetext{
${ }^{1}$ See Cheung [1969] on their role in risk allocation, and Stiglitz [1974] and Holmstrom [1979] on the basic incentive/insurance tradeoff emphasized in the agency literature. Reid [1976] and Rubin [1978] proposed instead that these contracts solve incentive problems on both sides of the equation, for principal and agent. Eswaran and Kotwal [1985] and Bhattacharyya and Lafontaine [1995] formalize these arguments.

${ }^{2}$ See Oyer [2004] and Lafontaine and Masten [2002] for applications of similar ideas to stock-option-based and truck-driver compensation schemes respectively. See also Dana and Spier [2001], Cachon and Larivière [2005] and Mortimer [2008] for related arguments for the reliance on share contracts in the video rental industry.
} 
model that illustrates how revenue sharing may be preferable to fixed fee contracts because they provide more flexible prices in contexts where values are unknown to both buyers and sellers. We also derive testable implications from our model. After describing our data in Section III, we show in Section IV that our data support the predictions of our flexible pricing model. We then discuss how many of the same data patterns make the usual risk sharing and marginal effort incentive arguments unlikely explanations for the use of sharing in this industry. Section V concludes.

\section{INSTITUTIONAL BACKGROUND AND THEORETICAL FRAMEWORK}

Although fixed salaries and prices are the norm in most employment and supplier/buyer relationships, share contracting arises also in a wide variety of contexts, both within and between firms. Sharing is particularly prevalent in certain industries or in relation to specific transactions, from real estate brokerage to author/publisher contracts, from auctioneer to lawyer compensation, and from retail real estate leasing to owner-operator contracts in trucking. It is ubiquitous, moreover, in the movie industry where we see talent being paid a share of revenues or profits (see Chisholm [1997], Weinstein [1998]), studios receiving a share of box office revenues from the movies they produce, distributors sharing box office revenues with exhibitors or theaters (see Hanssen [2002], Filson et al. [2005], Gil [2004]), and finally the same distributors sharing revenues with video stores (Cachon and Larivière [2005], Dana and Spier [2001], Mortimer [2008]).

Hanssen [2002] discusses the emergence of revenue sharing in the 1920's in the U.S. movie distribution industry, while Dana and Spier [2001], Cachon and Larivière [2005] and Mortimer [2008] describe how the U.S. video rental industry recently moved to this form of contracting. In all cases, the authors note that industry members chose to make the transition from fixed fees to revenue sharing. This begs the question as to why revenue sharing is preferred to fixed fees in these settings. In the remainder of this section, we describe the market and institutional features of Spanish movie distribution in some detail. We then develop a simple model that emphasizes the role of share contracts as a form of flexible pricing for distributors, one that maintains exhibitor incentives to allocate screens to movies efficiently while also allowing distributors to extract most of the downstream surplus and avoid some renegotiation costs.

\section{II(i). Institutional Setting}

We now describe the institutional features of the Spanish movie exhibition industry. Contracts in this industry are very similar to those used in the U.S. movie exhibition industry. For example, according to Filson et al. [2005], $89 \%$ of their 2,769 movie-exhibition contracts (all of them from one 
chain of thirteen theaters located in Saint Louis, Missouri) display the same sliding scale form that we find in our data. Revenue sharing is a much more recent phenomenon in this industry in Spain, however. While the U.S. industry moved to revenue sharing in the 1920's according to Hanssen [2002], industry insiders indicate that this form of contracting became popular in the 1970's in Spain. Before that, distributors were renting movies to exhibitors for a fixed upfront fee. Practitioners claim that the change to revenue sharing occurred because distributors saw this as a way to capture rents previously left with exhibitors. ${ }^{3}$

The assignment of movies to theaters in Spain begins with visits by distributors to exhibitors once or twice a year, at which point the distributors show their movie portfolios for the upcoming season. During these visits, the distributor and exhibitor agree on the number of copies of each movie that the exhibitor will take. This agreement does not yet define which theater, among those owned by the exhibitor, will show which movie because the release dates for most movies are not yet fixed. Note that the agreements are not predicated on any notion of exclusivity for the exhibitor locally. Once the release dates of a movie, and competing movies, are decided upon, distributors and exhibitors negotiate the assignment of movies to specific theaters. At this stage, distributor shares are still to be determined. These are negotiated sometime between a month and a week before the Spanish release date and before the distributor sends a physical movie copy to a theater. The parties negotiate separate contracts for each movie/theater combination. In other words, transactions are not bundled across movies in a theater, nor do they need to be identical for all theaters - or all of a particular exhibitor's theaters - showing the same movie. There is no variance in the type of contract, however. In all cases, the contracts stipulate series of weekly box office revenue shares that decrease with weeks since release, and never involve fixed fees. The relevant transaction that is priced in the contract, and for which renegotiation may occur as described further below, is therefore at the movie-theater-week level. Our contract term data are also at this level.

Exhibitors set movie ticket prices. They do not change the price to movie-goers in the short run based on movie quality or attendance (see

\footnotetext{
${ }^{3}$ After the move to share contracts in the U.S., exhibitors complained that the new shares were exorbitant compared to the fixed fees paid under the previous regime (Hanssen [2002], p. 388, footnote 25). This suggests again that the new share contracts allowed distributors to extract more of the exhibitor's profits. In Spain, the industry experimented with different forms of contracts before arriving at the current standard. The first revenue-sharing contracts stipulated sharing percentages (to distributors) based on total national box-office revenues per week or during the entire run of the movie contracted upon. However, these stipulated several ranges of revenues and shares to be applied to each range. Despite the increase in ex-ante contract complexity, industry practitioners indicate that ex-post renegotiation occurred in a large number of cases. These contract forms were abandoned and replaced by the current contractual form - which, according to industry members, was simpler to negotiate ex-ante - over the years that followed.
} 
Einav and Orbach [2007]). According to Filson et al. [2005], practitioners provide several explanations for this, including eliminating consumer uncertainty about prices, as well as the potential cost, in terms of goodwill, of charging more for more popular movies, and the difficulty of keeping track of which movie customers have paid for in multiplexes. For our purposes, we simply assume the price is constant and take it to be exogenous, though we allow it to vary across theaters. In reality, prices vary little across theaters in a city. With fixed movie ticket prices, revenue sharing amounts to per unit (per moviegoer) pricing, with the peculiarity that distributors get decreasing per movie-goer revenues as their share of revenues goes down with weeks since release.

Though the contract stipulates the share of box office revenues for a number of weeks on the screen, the number of weeks contracted upon is non-binding. The exhibitor, not the distributor, decides how long to keep a movie on the screen. The exhibitor can stop showing the movie at any time within the set of weeks contracted upon, or keep it longer than contracted for. Industry norms imply that the last distributor share stipulated in the contract applies to all weeks beyond those contracted upon. We argue that this set of decisions, of which movies to put on which screens and for how long, is the central role of exhibitors in this market. And consistent with Dana and Spier [2001], Cachon and Larivière [2005], and Ioannou, Mortimer and Mortimer [2011], we show, in our simple model below, that revenue sharing affects these decisions as well as the frequency of renegotiation requests.

Finally, regardless of the contract terms agreed upon for box-office revenue, the exhibitor retains full residual claims over concession profits. This occurs, we are told, in part because it would be prohibitively costly for exhibitors to track - and for distributors to verify - the concession sales associated with customers of each movie in multi-screen theaters. Moreover, given that they are local, exhibitors are in the best position to tailor concession offerings to the tastes of their customers, and supervise labor. From an incentive perspective, then, it is optimal to give them full ownership of the profits arising from such activities. ${ }^{4}$ Of course, the ownership of the concession profits also gives exhibitors incentives to keep on the screens movies that attract numerous customers into their theaters, and perhaps keep prices lower than what distributors would prefer (see Vogel [2001]). For simplicity, however, in modeling the interactions between exhibitor and distributor, we abstract from concession sales.

\footnotetext{
${ }^{4}$ See Slade [1996] for another context - gasoline retailing - where the downstream agent retains full residual claimant rights on other activities (i.e., car repairs or convenience store sales) regardless of the agreement that governs gasoline sales at the station. Note that while concession sales are only a small part of the total operations of a theater, they can make the difference between profitable and unprofitable operation (see Vogel [2001]).
} 


\section{II(ii). Revenue Sharing as Flexible Pricing}

Assume a distributor and an exhibitor contracting over revenues of movie $i$ in theater $j$. To focus on the effect of movie value uncertainty, we assume both parties are risk neutral, and there is no asymmetry of information. For simplicity, we also make a number of assumptions about the cost and revenues of the distributor and exhibitor. In particular, we assume that

- Movie $i$ will yield non-negative revenues for two periods only. First period revenues, $R_{l}$ of movie $i$ are distributed uniformly, i.e. $R_{l} \sim U[0, v]$, where $v$ is known to both parties. Second period revenues are also distributed uniformly, but bounded from above by the realization of revenues in period 1 , with decay rate $\gamma$ such that $R_{2} \sim U\left[0, \gamma R_{1}\right]$ where $0<\gamma<1$. Revenues beyond period 2 are $R_{3}=R_{4}=\ldots 0$.

- As per practice, the contract terms are determined prior to the release of the movie, and thus prior to receiving information about the realization of $R_{1}$.

- Theater operational costs, $k$, are constant from period to period, as are distributor operational costs, $k_{d}$. Since the latter are small, we normalize them to 0 .

- The theater has an outside option whose value is determined by the other movies released in periods 1 and 2 . We assume this opportunity cost is uniformly distributed in both periods such that $c_{t} \sim U[0, c]$ for $t=1,2$.

- The distributor can make 'take-it-or-leave it offers' and chooses the terms of the contract to maximize its profits.

As is standard practice in retail settings such as this one, the payments in this industry go from exhibitor to distributor, i.e., the exhibitor must pay its supplier (the owner of the movie rights). We compare three contractual forms, namely $i$ ) a contract that specifies revenue-sharing terms, one per period, $s_{1}$ and $s_{2}$, where $s_{t}$ is the share that goes to the distributor each period; ii) a contract that specifies lump-sum per-period fees to the distributor, $T_{1}$ and $T_{2}$; and iii) a contract that specifies an ex-ante unique lump-sum fees to the distributor, $T$. In addition, as mentioned above, the exhibitor can request an adjustment in its compensation when it finds the results of a movie in a given period are lower than expected. Because payments to the distributor are adjusted down automatically under revenue sharing, per Masten [1988] and Klein [1996], such adjustments should be needed less frequently under revenue sharing than under contracts that involve fixed fees. We account for this in our simple model by assuming that the distributor expects a higher cost of renegotiation under both period-by-period and upfront fixed-fee contracts than under revenue sharing. We use $G$ to represent this difference in renegotiation costs. As it is unclear which of the two types of fixed fee contracts would lead to 
higher renegotiation costs, for simplicity, we assume that $G$ is the same for both of these contract types. ${ }^{5}$

In Appendix A, we derive the optimal distributor shares and fixed fees for these three contract types. We show that while there is no closed-form solution for the optimal share in period 2, the revenue sharing contract is more profitable for the distributor than either the per-period or upfront fixed fee contracts under reasonable parameter values. In fact, if we assume that the theater expected opportunity cost, $c / 2$, should be similar to the revenues that the theater gets from movie $i$ in expectation, which is a share of about one half of expected revenues, or $.5^{*} v / 2$, we get that $\mathrm{c}$ can be approximated by $v / 2$. In that case, the condition for revenue sharing with $s_{2}=.5$ to be preferable to an upfront fixed fee contract becomes $G>\left(\gamma^{2}-\right.$ $2 \gamma+1.5) / 4 \gamma$, which cannot be satisfied for very small values of $\gamma$ (i.e., for $\gamma=0$ ), but will be easily satisfied for any reasonable per-period revenue retention parameter. Empirically, we find that second-period revenues are often in the 50 to $60 \%$ range of first-week results, values that would clearly lead to revenue sharing as a preferred mode of contracting. ${ }^{6}$

As described in Appendix A, our simple model yields several predictions about the optimal box office revenue share contract that we take to the data below. In particular, we find that in the optimal revenue-sharing contract, distributor shares are:

1. increasing in the expected revenues of the movie (higher $v / 2$ and $\gamma$ in the model);

2. decreasing in the number of periods since release;

3. decreasing in the opportunity cost of the exhibitor, $c$.

4. decreasing in the operational costs of the exhibitor, $k$.

In addition, we explore the effect of $(v / 2)$ and $\gamma$ on the rate of decline of distributor shares from period to period. We find that higher values of $\gamma$ are associated with a slower decline in distributor shares over time, not surprisingly. However, the effect of $v$ on the rate of change in distributor shares is ambiguous as both $s_{1}$ and $s_{2}$ are increasing in $v$. Since we cannot identify $v$ and $\gamma$ separately in our data, as both are associated with higher expected values for the movie, we explore the net effect of increases in the expected value of the movie on the rate of change in distributor shares empirically below.

\footnotetext{
${ }^{5}$ There are more potential terms to be renegotiated under per period fees but there is less at stake each time, so the cost of achieving a compromise may be lower per renegotiation under per period fees. Moreover, it is more likely that the movie is not shown in period 2 under per period than upfront fixed fees since the cost of showing the movie is 0 in period 2 under upfront fees. Of course, no renegotiation cost will be incurred if the movie is not shown. Thus, in the end, we cannot say a priori which form of contract will lead to higher renegotiation costs.

${ }^{6}$ For example, see www.the-numbers.com for data on week-to-week revenues in the U.S. market.
} 
In the next section, we describe our data and how we operationalize the different parameters or theater/movie characteristics in the model for our empirical analyses. Since our model assumes away risk aversion and incentive problems, it is important to note, before introducing the data and empirical methodology, that some of the model's predictions differ drastically from those of risk-sharing and double-sided moral hazard models. In particular, under risk-sharing the distributor should take higher shares for riskier movies, ceteris paribus, since the convention in the literature is that the distributor is less risk-averse than the exhibitor is. ${ }^{7}$ Similarly, under double-sided moral hazard, higher distributor shares would be optimal under circumstances where distributor effort matters more. Yet distributor effort is unlikely to be especially important for movies that, at the time of contracting, are already expected to do well. Thus the first implication above is central to the goal of this paper, and remains our main argument to demonstrate that flexible pricing, rather than risk sharing or doublesided moral hazard, is the main goal of revenue sharing in the movie distribution context. In our empirical analyses below, we provide evidence in support of our argument by comparing observations across movies with different revenue expectations and risk levels.

\section{THE DATA}

We have a unique data set with detailed information on the contracts used in the distribution of 510 movies shown in Spain in up to 96 different theaters between January, 2001, and June, 2002, for a total of 13,816 contracts. In this section, we summarize some of the main features of the data and contracts. Further details can be found in the data appendix, Appendix B.

The data are from the largest seven exhibitors in Spain. These firms account for roughly $10 \%$ of all theaters, $30 \%$ of all screens, and $40 \%$ of all box office revenues in the country. Some of the theaters in the data, however, are owned by distributors. Distributors rely on contracts with the same structure as those used for independent theaters when they show their own movies in their own theaters. Since it is less clear what distributor motivations might be in setting up contracts with their own theaters, we exclude these contracts from our analyses below. This does not eliminate any theaters from our data as theaters owned by distributors still show movies of other distributors. Moreover, we have verified that our results

\footnotetext{
${ }^{7}$ One reason to assume that distributors are less risk averse than exhibitors is that they distribute their movie in a variety of markets, and thus have more geographically diversified activities, than do the local exhibitors. Note that fixed fees are not a required feature of optimal contracts when non-linear schemes are allowed. However, in our context, the contracts are not non-linear, and thus a fixed fee would be required to obtain the desired distribution of income once the proportion is chosen to address risk-sharing or moral hazard issues.
} 
TABLE I

Descriptive Statistics

\begin{tabular}{|c|c|c|c|c|c|}
\hline Variable & Obs. & Mean & Std. Dev. & Min & Max \\
\hline $\begin{array}{l}\text { Movie/theater/week Level Data } \\
\text { Distributor Share }\end{array}$ & 52321 & 50.08 & 6.76 & 30 & 60.00 \\
\hline $\begin{array}{l}\text { Movie/theater Level Data } \\
\text { Max Distributor Share } \\
\text { Min Distributor Share } \\
\text { \# Weeks Stipulated } \\
\text { \# Weeks Between Max and Min Share } \\
\text { \# Weeks at Max Share } \\
\text { Actual Run Length } \\
\text { Distributor Share }^{1}\end{array}$ & $\begin{array}{r}10167 \\
10167 \\
10167 \\
10167 \\
10167 \\
3706 \\
10167\end{array}$ & $\begin{array}{r}57.58 \\
44.02 \\
5.22 \\
3.38 \\
1.28 \\
4.16 \\
50.61\end{array}$ & $\begin{array}{l}3.75 \\
5.84 \\
2.83 \\
2.08 \\
0.56 \\
3.35 \\
3.94\end{array}$ & $\begin{array}{r}30 \\
30 \\
1 \\
-1^{\dagger} \\
1 \\
1 \\
30\end{array}$ & $\begin{array}{l}60.00 \\
60.00 \\
31 \\
17 \\
10 \\
33 \\
60.00\end{array}$ \\
\hline $\begin{array}{l}\text { Movie Level Data } \\
\text { Spain Box Office (€M) } \\
\text { U.S. Release } \\
\text { U.S. Box Office (\$M) } \\
\text { Movie Duration (in minutes) } \\
\text { Released during Christmas week? } \\
\text { Released during Other Major Holiday? } \\
\text { U.S. Box Office of Concurrent Releases } \\
\text { Distributor Share } \\
\text { Max Distributor Share } \\
\text { Min Distributor Share } \\
\text { \# Weeks Stipulated } \\
\text { \# Weeks Between Max and Min Share } \\
\text { \# Weeks at Max Share } \\
\text { \# } \text { Actual Run Length }^{3} \\
\text { Actul }^{3}\end{array}$ & $\begin{array}{l}430 \\
430 \\
269 \\
430 \\
430 \\
430 \\
430 \\
430 \\
430 \\
430 \\
430 \\
430 \\
430 \\
313\end{array}$ & $\begin{array}{r}2.28 \\
0.63 \\
47.27 \\
107.04 \\
0.03 \\
0.11 \\
129.65 \\
49.30 \\
55.78 \\
44.65 \\
4.30 \\
2.58 \\
1.18 \\
3.66\end{array}$ & $\begin{array}{r}4.01 \\
0.48 \\
61.46 \\
16.53 \\
0.18 \\
0.32 \\
93.20 \\
3.59 \\
4.51 \\
4.56 \\
2.24 \\
1.55 \\
0.40 \\
3.34\end{array}$ & $\begin{array}{l}0.002 \\
0 \\
0.001^{\dagger \dagger} \\
75 \\
0 \\
0 \\
0 \\
30.00 \\
30.00 \\
30.00 \\
1 \\
0 \\
1 \\
1\end{array}$ & $\begin{array}{c}30.93 \\
1 \\
403.7 \\
186 \\
1 \\
1 \\
403.7 \\
60.00 \\
60.00 \\
60.00 \\
22 \\
8.43 \\
4 \\
26\end{array}$ \\
\hline $\begin{array}{l}\text { Theater Level Data } \\
\text { \# Screens } \\
\text { Exhibitor Market Share (in seats) } \\
\text { Theater Age }\end{array}$ & $\begin{array}{l}91 \\
91 \\
70\end{array}$ & $\begin{array}{l}7.32 \\
0.37 \\
6.03\end{array}$ & $\begin{array}{l}3.51 \\
0.32 \\
7.66\end{array}$ & $\begin{array}{l}1 \\
0.02 \\
0\end{array}$ & $\begin{array}{r}17 \\
1 \\
54\end{array}$ \\
\hline
\end{tabular}

${ }^{1}$ The data are at the movie/theater/week level. The movie/theater level information is generated by averaging across weeks at each theater.

${ }^{2}$ The data are at the movie/theater/week level. The movie-level information is generated by first averaging across weeks at a theater, and then across theaters.

${ }^{3}$ The data are at the movie/theater level. The movie level data represent averages across theaters.

The minimum number of weeks is minus one here because one movie in the sample started at a low distributor share and then the share went up after a week. The distributor gave up first week revenues in order to convince exhibitors to show the movie, a Japanese movie that had not been released in the U.S. previously.

${ }^{\dagger}$ This U.S. Box Office revenue figure is for 'Strictly Sinatra,' a U.K. production that collected \$1,232 during its one week on U.S. screens, and was later released in Spain.

are qualitatively the same if we include the contracts of distributors showing their own movies on their own screens. We also exclude a few contracts ( 965 of them) that do not represent first-run contracts. Our final sample relates to 430 movies shown in up to 91 theaters owned by our seven exhibitors in 51 different cities, for a total of 10,167 contracts. These 430 movies were distributed by 22 different distributors. Note that during the eighteen months that our data cover, the average theater showed 111 movies, while the average distributor dealt with 40 theaters for each of the 20 movies it distributed, or, in other words, some 800 contracts.

In Table I, we present descriptive statistics for our variables of interest, beginning with our main dependent variable, distributor share, which we 
observe at the movie/theater/week level. We then describe data available on a per-contract (or movie/theater) rather than per-week basis. This includes information on the terms of the contract, namely the maximum and minimum distributor shares stipulated in the contract, along with the number of weeks that these contract terms apply to. We also present here data on the actual run length of the movie per theater, which we have for a subset of our data. Finally, we show distributor shares again. Comparing the mean here versus that at the movie theatre/week level reveals that weighing by the number of weeks that each movie is contracted on does not affect the mean distributor share much at all.

In the next part of Table I we summarize those variables that are available at the movie level, namely the box office results of the movie in Spain, as well as whether or not the movie was released in the U.S., and if so, its U.S. box office results. We also report data on the duration of the movies, in minutes, as well as information concerning the timing of the releases, whether at Christmas or at a time corresponding to other major holidays, and the 'known' value of other movies released at the same time, measured by their total U.S. box office. ${ }^{8}$ We report distributor shares here as well. When compared to the movie/theater level, averaging at the movie level gives as much weight to movies shown in fewer theaters as to more popular movies shown in several theaters. Consistent with our explanation for the shares, we find that the average distributor share is now somewhat lower. The maximum share stipulated is also lower as are the number of weeks contracted on and actual movie run length.

In the last part of Table I, we present information available at the theater level, including data on the size of the theaters (number of screens), exhibitor market share, calculated as the proportion of all theater seats in the city accounted for by the owner of theater $i$, and the age of the theaters. ${ }^{9}$ We use these data to measure both theater costs $(k)$ and potentially theater bargaining power, which in our model would be captured by a higher potential return from showing an alternative movie, namely a higher $c .^{10}$

In the contracts, the stipulated revenue share for the distributors averages about $50 \%$. In the literature on sharecropping, authors also have found a tendency for contracts to involve a 50/50 split. However, while

\footnotetext{
${ }^{8}$ We use data on all U.S.-released movies that are released in Spain during the period of our sample to create this variable, whether or not we have contract data for the movies in question.

${ }^{9}$ Unfortunately, we could only ascertain the construction year for 70 of the 91 theaters in the data.

${ }^{10}$ This approach is consistent with Svejnar [1986], who suggests that asymmetric bargaining power in negotiations stems from factors related to each bargainer's relative fear of disagreement. Thus better outside options for theaters yield better bargaining power vis-à-vis distributors. See also Ho [2009] for a recent application.
} 
sharecropping contracts tend to stipulate this division directly, here it is obtained by having the distributor receive more than $57 \%$ of box office revenues on average for the first week or two, and then a lower share in the following weeks, down to an average share of $44 \%$ at the end of the predicted run of the movie.

Distributors specify shares for about five weeks per movie on average, with a standard deviation of almost three weeks. Thus a number of movies are contracted upon for very short periods of time, basically just a couple of weeks. When we look at the number of weeks stipulated variable in the third part of Table I, where the data are weighted by movie instead of movie/theater, we find a much lower average number of weeks. As mentioned above, this indicates that less popular movies, shown in fewer theaters, are contracted upon for shorter periods of time. Comparing the data at the movie/theater and movie level also reveals that the extra week contracted upon corresponds mostly to more time going from maximum to minimum distributor share for the more popular movies, not more time at the maximum. Finally, the data on realized movie run lengths show that movies last an average of about one month on the screens, but that there is more variance in movie run durations than in stipulated contract periods. Moreover the actual run lengths are, on average, shorter than the period contracted on. This confirms that the contracts are not binding when it comes to keeping movies on screens exhibitors can pull movies before the end of the period for which terms are stipulated in the contract. At the same time, some movies remain on screens beyond the number of weeks contracted upon.

Sixty-three per cent of movies released in Spain are released first in the U.S. These movies are shown in more theaters in Spain than non-U.S. released movies, as indicated by the fact that the proportion of movies released in the U.S. is seventy-three percent when calculated on a movie/ theater basis (not shown). The movies released in the U.S. prior to their release in Spain collected an average of $\$ 47$ million during their U.S. run. However, there is much variance within this set as well. Note that movies first released in the U.S. are not necessarily produced in the U.S. - most U.K. movies are shown in the U.S. prior to their release in Spain, for example.

As for theater characteristics, exhibitors control more than a third of all the seats in their market (city) on average. In some cases $(19 \%$ of theaters), the owners have $100 \%$ of the local capacity. Finally, the majority of the theaters in the data are modern multi-screen theaters: theaters have seven screens on average, and have been opened for only six years, though some have been in existence for much longer. In our sample, only six theaters opened prior to 1990 with the oldest opening in 1948. These older theaters have significantly fewer screens (roughly 4 screens per theater) and a smaller number of total seats $(1,100$ versus, 1,650$)$. 
TABLE II

Predicting Spanish Box Office Revenues for U.S. Released Movies

\begin{tabular}{lcccc}
\hline Dep Variable: & $\begin{array}{c}\text { Spain Box } \\
\text { Office }(€ \mathrm{M}) \\
(1)\end{array}$ & $\begin{array}{c}\text { Ln (Spain } \\
\text { Box Office) } \\
(2)\end{array}$ & $\begin{array}{c}\% \text { Deviation } \\
\text { from } \\
(1)\end{array}$ & $\begin{array}{c}\% \text { Deviation } \\
\text { from } \\
(2)\end{array}$ \\
\hline U.S. Box Office $(\$ \mathrm{M})$ & $0.060^{* * *}$ & & $-0.005^{* * *}$ & \\
ln (U.S. Box Office) & $(0.005)$ & $0.610^{* * *}$ & $(0.002)$ & $-0.014^{* * *}$ \\
& & $(0.050)$ & & $(0.003)$ \\
Constant & 0.106 & $3.592^{* * *}$ & $1.164^{* * *}$ & $0.306^{* * *}$ \\
& $(0.177)$ & $(0.869)$ & $(0.193)$ & $(0.052)$ \\
Observations & 269 & 269 & 269 & 269 \\
Mean Squared Error & 6.55 & 2.31 & 4.10 & 0.01 \\
R-squared & 0.68 & 0.43 & 0.03 & 0.12 \\
\hline
\end{tabular}

Robust standard errors in parentheses. * significant at $10 \% ; * *$ significant at $5 \%$; ** significant at $1 \%$. There is an 0.82 correlation between U.S. Box Office and Spain Box Office, and 0.65 correlation between their log counterparts.

\section{EMPIRICAL METHODOLOGY AND RESULTS}

In this section, we test the predictions from Section II, starting with the effect of movie value on distributor shares and their evolution over time since release. We test these predictions in two steps - first, we show that a movie's results in the U.S. market can be used to predict how well the same movie will do in Spain, and that such predictions are more precise for movies that did better in the U.S. market. We then show that, as predicted, distributors request higher shares for those movies that they predict will do better in Spain. Next we examine the effects of exhibitor opportunity costs, using the value of alternative movies released in the same week as well as a measure of their share of the local exhibition markets, and the effect of exhibitor operational costs, which we approximate using theater size and age. Note that these effects can also be interpreted in terms of increased exhibitor bargaining power resulting from more market power, better alternatives or better location or facilities. Finally, we test the implications of our model for the frequency and form of contract renegotiation in this industry. This last piece of evidence also will be important when we evaluate the role of risk-sharing and double-sided moral hazard as explanations for the use of revenue sharing contracts in this industry in Section IV(iv).

\section{IV(i). Predicting Movie Success in Spain}

Table II shows how useful information about U.S. box office is in predicting Spanish box office figures. The regression results indicate that boxoffice revenues in the two countries are highly correlated, as shown in the first two columns. They also show in columns 3 and 4, where the dependent variables are the absolute value of the error term from the estimations in columns 1 and 2, respectively, divided by the predicted value of Spanish 


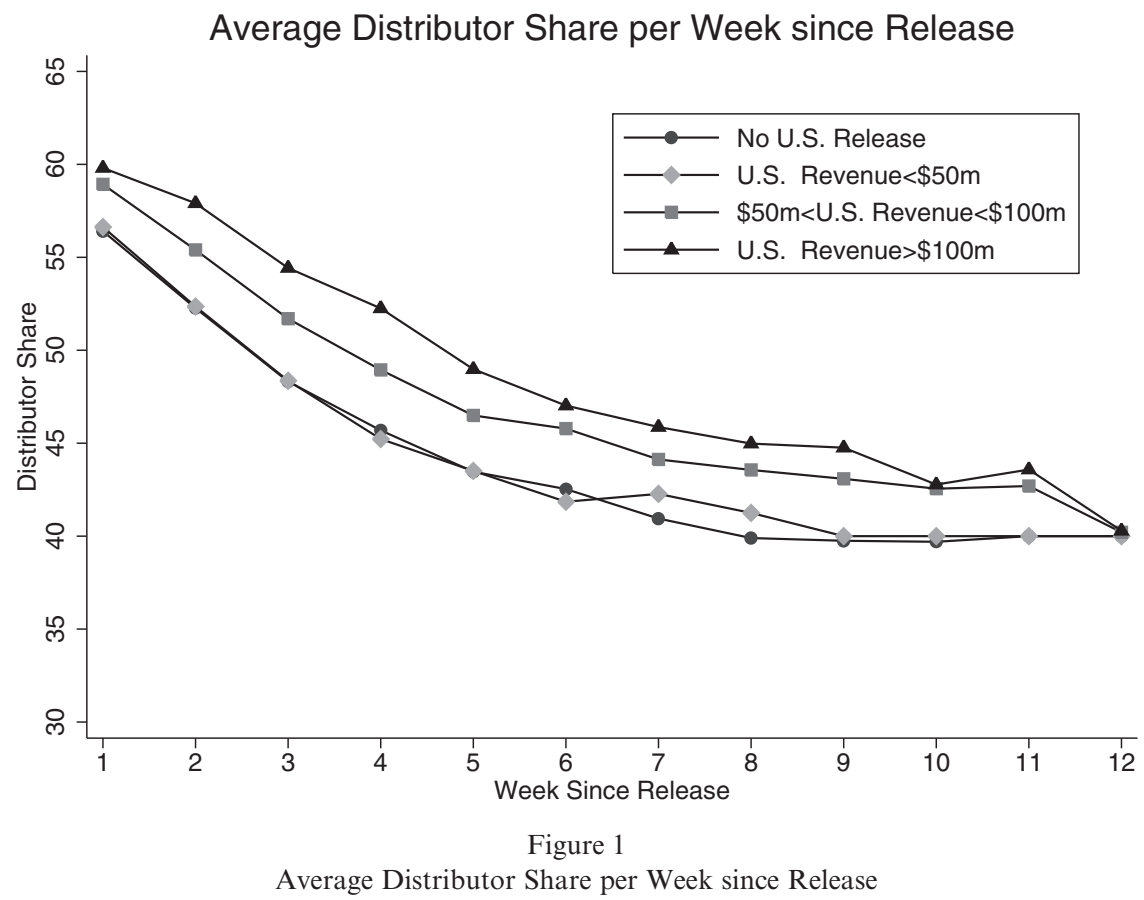

Note: The set of movies within each one of the four movie categories is changing across weeks due to differences in the length of each movie contract.

box office in these same regressions, that the prediction errors are also smaller for movies that do better in the U.S.

Interviews with distribution and exhibition managers in Spain confirmed the importance of U.S. market information in their evaluation of the market potential for a movie in Spain. First, the managers indicated that they do rely on box office revenues in the U.S. to generate forecasts of movie revenues in Spain. Second, the managers confirmed that they view movies that have collected high levels of U.S. box office revenues as least risky, followed by those that collect medium and then low levels of revenues in the U.S. Managers also reported that local or European movies not previously released in the U.S. are the riskiest type of movies that they handle since they do not come to them with a market outcome that they can rely upon.

\section{IV(ii). Distributor Shares and Movie Success In Spain}

Figure 1 shows how distributor shares change over weeks since release for different categories of movies, where the categories are defined using box 
office outcomes in the U.S. ${ }^{11}$ This figure illustrates two important patterns, both of which are consistent with our predictions. First, even though only more successful movies are contracted upon for long periods of time, average distributor shares are systematically lower for all categories of movies the longer the time since release. Second, Figure 1 shows that distributors obtain a larger share of revenues for movies that are expected to do well. More specifically, average distributor shares are greatest for the set of 33 movies that did best in the U.S., followed by those 51 that did between $\$ 50 \mathrm{M}$ and $\$ 100 \mathrm{M}$ in the U.S. These differences, moreover, are statistically significant up to week 11 . Movies that did relatively poorly in the U.S., namely the 185 movies that obtained less than $\$ 50$ million in box office there, and non-U.S. released movies (161) are contracted upon using very similar, and statistically not different, shares on average. ${ }^{12}$

One potential explanation for the patterns in Figure 1 that would be consistent with risk-sharing but that we can rule out is that distributors of non-U.S. released movies may be smaller firms, and hence more likely to be risk averse, than the distributors of blockbuster movies. We find the same patterns (not shown) in distributor shares after controlling for distributor fixed effects - in other words, even within distributors, blockbusters command larger distributor shares but shares are the same for movies that did poorly in the U.S. and those that were never released there. We explore the relationship between distributor share and movie success further in Table III, where we show how distributor shares stipulated in the contract relate to U.S. box office revenues and how they change with weeks since release. We first show results obtained when we do not control for any fixed effects, followed by results with theater, and then theater and calendar week, and finally theater, week and week-since-release fixed effects. We also control for movie duration, in minutes, under the assumption that it might affect its pricing. Since our data are at the movie/theater/week level, and we expect contracts to be correlated within movies, and possibly across theaters, we cluster standard errors at the movie and theater level (two-way clustering).

Results in Table III are consistent across specifications, which implies that the patterns in distributor shares and how they relate to a movie's popularity are unaffected by the inclusion of seasonality effects and theater characteristics. The results are also consistent with the predictions of our simple flexible pricing model. In all specifications, while the coefficient on

\footnotetext{
${ }^{11}$ In Figure 1, the set of movies within each one of the four movie categories is changing across weeks due to differences in the length of each movie contract.

${ }^{12}$ Movies not released in the U.S. average 1.13 million Euros in Spain versus 1.16 million Euros for movies that were released in the U.S. but collected less than $\$ 50$ million in box office. While the mean results in Spain are not statistically different for these two sets of movies, the standard deviation in box office results is statistically greater for movies not previously released in the U.S.
} 
TABLE III

Distributor Shares Per Movie/Theater/Week

\begin{tabular}{lccccc}
\hline Independent Variable: & $(1)$ & $(2)$ & $(3)$ & $(4)$ & $(5)$ \\
\hline U.S. Release & $-3.12^{* * *}$ & $-3.13^{* * *}$ & $-3.07^{* * *}$ & $-2.75^{* *}$ & $-2.15^{*}$ \\
& $(0.76)$ & $(0.75)$ & $(0.82)$ & $(1.26)$ & $(1.28)$ \\
Ln[1+U.S. Box Office] & $1.12^{* * *}$ & $1.11^{* * *}$ & $1.10^{* * *}$ & $1.01^{* * *}$ & $0.76^{*}$ \\
& $(0.19)$ & $(0.19)$ & $(0.20)$ & $(0.38)$ & $(0.40)$ \\
Standard Deviation of & & & & & -1.03 \\
Forecast Error & & & & $(1.07)$ \\
Week Since Release & $-2.16^{* * *}$ & $-2.19^{* * *}$ & $-2.19^{* * *}$ & & \\
& $(0.12)$ & $(0.12)$ & $(0.12)$ & & \\
Week Since Release*U.S. & $0.003^{* * *}$ & $0.003^{* * *}$ & $0.002^{* * *}$ & $0.005^{* * *}$ & $0.005^{* * *}$ \\
Box Office & $(0.001)$ & $(0.001)$ & $(0.001)$ & $(0.002)$ & $(0.002)$ \\
Christmas Week & 0.81 & 0.84 & & & \\
& $(0.83)$ & $(0.82)$ & & & \\
Other Holiday Week & 0.014 & 0.020 & & & \\
& $(0.26)$ & $(0.25)$ & & & \\
Ln[1+U.S. Box Office of & -0.060 & -0.051 & -0.063 & 0.38 & 0.44 \\
Concurrent Releases] & $(0.16)$ & $(0.16)$ & $(0.16)$ & $(0.59)$ & $(0.59)$ \\
Movie Duration (in minutes) & 0.011 & 0.011 & 0.013 & 0.026 & 0.025 \\
& $(0.014)$ & $(0.014)$ & $(0.014)$ & $(0.019)$ & $(0.019)$ \\
Constant & $55.4^{* * *}$ & $55.5^{* * *}$ & $55.4^{* * *}$ & $42.7^{* * *}$ & $44.2^{* * *}$ \\
& $(1.66)$ & $(1.65)$ & $(1.73)$ & $(3.70)$ & $(4.05)$ \\
Theater FE & No & Yes & No & No & No \\
Week-Theater FE & No & No & Yes & No & No \\
Week-Theater-Week since & No & No & No & Yes & Yes \\
Release FE & & & & & \\
Observations & 52321 & 52321 & 52321 & 52321 & 52321 \\
R-squared & 0.56 & 0.56 & 0.61 & 0.86 & 0.86 \\
\hline
\end{tabular}

Standard errors clustered at both the movie and theater level (two-way clustering), in parentheses.

* significant at $10 \%$;* significant at $5 \%$; ** significant at $1 \%$.

U.S. release is negative contrary to what one might expect, the coefficient on ( $\log )$ U.S. box office is such that distributors of movies that achieve even very modest results in the U.S., in the order of $\$ 15 \mathrm{M}$ to $\$ 17 \mathrm{M}$ in box office revenues, obtain shares that are as high as those of non-U.S. released movies. ${ }^{13}$ This explains why movies that did below $\$ 50 \mathrm{M}$ in the U.S., which averaged about $\$ 17 \mathrm{M}$ in that market, show shares that are so similar to those of non-U.S. released films in Figure 1.

As mentioned previously, we cannot distinguish $v$ and $\gamma$ in our data. However, our model predicts that a higher $\gamma$ should lead to slower decreases in distributor shares, while the relation between $v$ and the rate of decrease in distributor shares is ambiguous. Results in Table III, however, show that distributor shares in fact do decline less rapidly over time since release for movies that are expected to do better in Spain. Thus the overall effect of higher expected movie revenues (combination of $v$ and $\gamma$ ) is to slow the decrease in distributor shares over time since release. Specifically, while these shares decline by more than two percentage points each week, per the coefficient on weeks since release, the positive interaction effect between

${ }^{13}$ For example, in column $1, \exp (3.14 / 1.13)-1=15.1$. 
U.S. box office and week since release implies that every 10 million dollars of U.S. box office reduces the weekly decline in distributor share by 0.03 percentage points, or $1.39 \%(100 * 0.03 / 2.16)$ based on results in column 1 .

Results in the first two columns of Table III, where we do not control for seasonality using fixed effects, allow us also to consider the effect of high demand by moviegoers, usually associated with major holidays such as Christmas and other holidays, and the effect of the exhibitor opportunity cost, measured by the U.S. box office results of all movies released the same week as movie $i$, on distributor shares. We find that while the directions of the effects are consistent with our flexible pricing model, none of these variables has statistically significant effects on distributor shares. ${ }^{14}$ Similarly, distributor shares are higher for longer movies, but this effect is also not significant. Note that a priori this result could have gone either way since one might expect that lengthy movies do not allow as many showings, resulting in lower box office results (or put equivalently, higher theater operational costs). However, longer duration movies also tend to be good (in fact, in our data one extra minute of movie length is associated with 1.5 additional million of U.S. box office); or rather, good movies can afford to be long. In any case, our main results remain the same when we exclude movie duration from our regressions.

In the last column of Table III, we add one other variable, 'Standard Deviation of Forecast Error,' to our most flexible specification. This variable is defined as the standard deviation of the forecast error for the group of movies that achieved similar box office outcomes in the U.S., where the groups are deciles of the U.S. box office revenue distribution, and the forecast errors are obtained from the regression in column 2 of Table II. We created an eleventh category by grouping all movies not released in the U.S., and using the deviation of their results from the mean results of the group as our forecast error. We then calculated the standard deviation of the forecast errors for each group. As expected, based on our flexible pricing model where prices should be based on expected values only, results in Table III show no relationship between the 'Standard Deviation of Forecast Error' and distributor share. Note that, whereas this lack of correlation between distributor share and the variability of forecast error is very consistent with flexible pricing, it is very detrimental to the risksharing argument which predicts higher distributor shares for riskier movies once expected revenues are controlled for (assuming again, per the literature, that exhibitors are more risk-averse than distributors).

Finally, while not shown in the table, we also examined how movie genre might affect observed shares, under the presumption that box office results may be less predictable for some movie genres (e.g., science fiction vs.

\footnotetext{
${ }^{14}$ We also examined the effect of only same genre concurrent releases. Again, we found that this measure of opportunity cost never had a significant effect on the contracted shares. 
TABLE IV

Distributor Shares Per Movie/Theater/Week

\begin{tabular}{lccc}
\hline Independent Variables: & $(1)$ & $(2)$ & $(3)$ \\
\hline U.S. Release & $-3.10^{* * *}$ & $-4.19^{* * *}$ & $-3.89^{* * *}$ \\
Ln[1 + U.S. Box Office] & $(0.75)$ & $(0.81)$ & $(0.84)$ \\
Week Since Release & $1.10^{* * *}$ & $1.54^{* * *}$ & $1.46^{* * *}$ \\
& $(0.19)$ & $(0.19)$ & $(0.20)$ \\
Week Since Release*U.S. Box Office & $-2.14^{* * *}$ & & \\
Theater Age & $(0.12)$ & & \\
& $0.003^{* * *}$ & 0.0004 & 0.0003 \\
Screens & $(0.0005)$ & $(0.0005)$ & $(0.0005)$ \\
& -0.034 & $-0.081^{* * *}$ & $-0.078^{* * *}$ \\
Exhibitor Market Share & $(0.031)$ & $(0.026)$ & $(0.025)$ \\
Christmas Week & -0.021 & $-0.044^{*}$ & -0.038 \\
& $(0.017)$ & $(0.026)$ & $(0.024)$ \\
Other Holiday Week & $-0.21^{*}$ & -0.15 & -0.15 \\
Ln[1+U.S. Box Office of Concurrent Releases] & $(0.12)$ & $(0.14)$ & $(0.13)$ \\
Movie Duration (minutes) & 0.88 & 1.16 & \\
Constant & $(0.82)$ & $(0.94)$ & \\
Week since Release Fixed Effects & 0.007 & -0.012 & \\
Week Fixed Effects & $(0.26)$ & $(0.24)$ & -0.15 \\
Observations & $(0.066$ & -0.11 & $(0.15)$ \\
R-squared & 0.011 & $(0.15)$ & 0.018 \\
& $(0.013)$ & 0.016 & $(0.013)$ \\
\hline
\end{tabular}

Standard errors clustered at both the movie and theater level (two-way clustering), in parentheses.

* significant at $10 \%$;* significant at $5 \% ; * * *$ significant at $1 \%$.

mainstream comedies). In no case were movie genre fixed effects significant as a group in our regressions if we included other types of fixed effects. Moreover, their inclusion did not affect any of the results above.

In Table IV, we shun the use of theater fixed effects to explore how theater characteristics affect distributor and exhibitor shares. We find first that, consistent with the fact that the introduction of theater fixed effects did not alter the conclusions we reached in Table III, our results above also are robust to replacing these fixed effects with theater characteristics. Moreover, the evidence concerning the effects of theater characteristics is also consistent with the predictions of our flexible pricing argument. In particular, we find that older theaters, which we expect to have higher costs but also potentially to be located in more valuable locations, get larger shares of box office revenue. In addition, distributors get lower shares when dealing with larger theaters and/or exhibitors with larger market shares.

Though not shown in the tables, we have verified the robustness of our results in several other ways. In particular, we reproduced all our analyses using the average distributor share per movie and week since release, rather 
TABLE V

Movie/Theater Contract Terms

\begin{tabular}{|c|c|c|c|c|c|c|}
\hline \multirow[b]{2}{*}{ U.S. Release } & \multicolumn{2}{|c|}{ Max Share } & \multicolumn{2}{|c|}{ Weeks Contracted } & \multicolumn{2}{|c|}{ Actual Run Length } \\
\hline & $\begin{array}{l}-2.60^{* * *} \\
(0.71)\end{array}$ & $\begin{array}{l}-2.18 * * * \\
(0.80)\end{array}$ & $\begin{array}{l}-2.48 * * * \\
(0.44)\end{array}$ & $\begin{array}{l}-1.94 * * * \\
(0.36)\end{array}$ & $\begin{array}{l}-2.95 * * * \\
(0.62)\end{array}$ & $\begin{array}{l}-2.53 * * * \\
(0.50)\end{array}$ \\
\hline Ln[1 + U.S. Box Office $]$ & $\begin{array}{l}1.10^{* * *} \\
(0.14)\end{array}$ & $\begin{array}{l}1.06^{* * *} \\
(0.23)\end{array}$ & $\begin{array}{l}0.96^{* * * *} \\
(0.13)\end{array}$ & $\begin{array}{l}0.79^{* * *} \\
(0.11)\end{array}$ & $\begin{array}{l}1.11^{* * *} \\
(0.18)\end{array}$ & $\begin{array}{l}1.02^{* * *} \\
(0.15)\end{array}$ \\
\hline Theater Age & $\begin{array}{l}-0.091 * * * \\
(0.033)\end{array}$ & & $\begin{array}{l}-0.069 * * * \\
(0.020)\end{array}$ & & $\begin{array}{r}0.036^{*} \\
(0.020)\end{array}$ & \\
\hline Screens & $\begin{array}{l}-0.051 \\
(0.035)\end{array}$ & & $\begin{array}{c}0.066 \\
(0.041)\end{array}$ & & $\begin{array}{l}0.15 * * * \\
(0.036)\end{array}$ & \\
\hline Exhibitor Market Share & $\begin{array}{l}-0.25 \\
(0.23)\end{array}$ & & $\begin{array}{l}-0.65^{* *} \\
(0.31)\end{array}$ & & $\begin{array}{l}-0.58^{* *} \\
(0.29)\end{array}$ & \\
\hline Christmas Week & $\begin{array}{c}0.45 \\
(0.83)\end{array}$ & & $\begin{array}{l}1.30^{*} \\
(0.77)\end{array}$ & & $\begin{array}{c}1.17 \\
(1.43)\end{array}$ & \\
\hline Other Holiday Week & $\begin{array}{l}0.81^{* *} \\
(0.41)\end{array}$ & & $\begin{array}{l}0.45 \\
(0.27)\end{array}$ & & $\begin{array}{c}0.59 \\
(0.56)\end{array}$ & \\
\hline $\begin{array}{l}\text { Ln[1+U.S. Box Office of } \\
\text { Concurrent Releases] }\end{array}$ & $\begin{array}{c}-0.025 \\
(0.12)\end{array}$ & $\begin{array}{c}0.074 \\
(0.30)\end{array}$ & $\begin{array}{c}-0.045 \\
(0.084)\end{array}$ & $\begin{array}{l}-0.22 \\
(0.16)\end{array}$ & $\begin{array}{c}-0.14 \\
(0.14)\end{array}$ & $\begin{array}{l}-0.34 \\
(0.24)\end{array}$ \\
\hline Constant & $\begin{array}{l}57.5^{* * * *} \\
(0.82)\end{array}$ & $\begin{array}{l}56.4 * * * \\
(1.48)\end{array}$ & $\begin{array}{l}4.45^{* * *} \\
(0.61)\end{array}$ & $\begin{array}{l}6.67 * * * \\
(0.79)\end{array}$ & $\begin{array}{l}2.37 * * * \\
(0.73)\end{array}$ & $\begin{array}{l}4.69 * * * \\
(1.15)\end{array}$ \\
\hline Movie-Release Week FE & No & Yes & No & Yes & No & Yes \\
\hline Theater FE & No & Yes & No & Yes & No & Yes \\
\hline Observations & 9110 & 10167 & 9110 & 10167 & 3472 & 3706 \\
\hline R-Squared & 0.15 & 0.27 & 0.19 & 0.42 & 0.18 & 0.45 \\
\hline
\end{tabular}

Standard errors clustered at both the movie and theater level (two-way clustering), in parentheses.

* significant at $10 \% ; * *$ significant at $5 \% ; * * *$ significant at $1 \%$.

than the actual movie/theater/week since release share data, as our dependent variable. Note that this average share abstracts from variation in distributor shares across theaters within a movie and week since release, which amounts to eliminating only $6 \%$ of the total variation in our data. Regression analyses with this alternative dependent variable also weigh movies that did not do so well at the box office as much as movies released in many more theaters, and ensures that the significance of our results is not an artifact of using several observations per movie week (though this concern is also alleviated via clustering in the regressions above). We focus on results obtained with the more detailed data above since the use of an average share across theaters prevents us from examining the impact of theater specific characteristics. In other specifications we also added distributor, as well as distributor/theater, fixed effects to eliminate the possibility that matches between distributors and theaters (or exhibitors) could bias our results. In all cases, we found that our results above were robust to these alternative specifications.

Finally, in Table V, we show how the maximum distributor shares stipulated in each contract, the number of weeks the contract covers, and the number of weeks that the movie actually is kept on the screen (Actual Run Length) all relate to the predicted success of the movie, as captured by U.S. release and U.S. box office revenues. These analyses involve contract-level variables so the number of observations is limited to the total number of 
contracts in our data. This also constrains the type of fixed effects we can include. For each variable, we show results when we include no fixed effects, followed by results obtained with theater and movie week-of-release fixed effects.

Our flexible pricing model for share contracts in this industry implies that movies with higher expected revenues in the Spanish market namely those that collected higher box office revenues in the U.S.- should have higher starting maximum shares and longer movie runs. We show evidence of the former in the first two columns and of the latter in the last two columns. Even though the distributor keeps a higher share of the revenues for a longer period, exhibitors keep the higher U.S. box office movies running longer - given high Spanish attendance for these, it is profitable for exhibitors to keep showing them despite the more adverse contract terms. We also find that contracts for higher U.S. box-office movies have higher maximum distributor shares and that they involve sharing terms for a greater number of weeks than contracts of movies that were not as successful in their U.S. run. Since there is less uncertainty about the demand for these movies, these contracts are more effective in providing the adequate incentives to exhibitors to keep the movie on the screen for a longer period.

Results in Table $\mathrm{V}$ also show that maximum distributor shares are lower when movies are shown in older and in larger theaters, in terms of number of screens, and in those theaters owned by higher market-share exhibitors. We find also that older theaters contract for fewer weeks, but keep movies longer on their screens, while theaters with more screens both contract for more weeks and keep movies longer on their screens. The latter is likely due to the flexibility that multiplexes benefit from as they can move the movie to rooms with fewer seats over time. Theaters owned by high-market share exhibitors, on the other hand, tend to keep movies on the screen fewer weeks, on average. Finally, movies released during holiday weeks or around Christmas are contracted upon for more weeks on average, but their actual runs are not statistically significantly longer than that of movies released in other weeks.

In sum, results in Table $\mathrm{V}$ confirm that movies with even modest outcomes in the U.S. ( $>\$ 8 \mathrm{~m}$ to $\$ 14 \mathrm{~m}$ depending on the specification) have higher max shares, are contracted upon for longer periods of time, and are kept on the screen longer than non-U.S. released movies. These and other results in the table are consistent with the predictions from our model.

\section{IV(iii). Movie Results and Ex-post Renegotiation}

As noted earlier, it is standard practice in the industry for distributors to renegotiate exhibitor shares when movie revenues are unexpectedly low 
for a given week. ${ }^{15}$ Although accounts are settled only at the end of the movie's run, industry insiders point out that distributors renegotiate weekly shares, and that they can easily identify the weeks for which shares will be renegotiated as they observe the weekly results for their movies. In a sample of roughly 19,000 theater/movie/week observations, Gil [2004] finds that distributors agreed to modify the share paid to exhibitors one out of every two weeks on average. In no case do they renegotiate in favor of the distributor. In other words, it is because the participation constraint of the exhibitor is not satisfied, and not because of problems with low distributor compensation, that the parties renegotiate. ${ }^{16}$

In our view, the one-sidedness of the renegotiation process results from - and further encourages - aggressive setting of contract terms on the part of distributors. Specifically, the distributors' desire to extract most of the downstream profits leads them to offer terms that may not satisfy the exhibitors' participation constraint in expectation, and this results in frequent requests for adjustments ex post. The frequency with which they engage in renegotiations, combined with the value of their future relationship, gives both parties incentives to agree to new terms fairly quickly. Thus the cost of renegotiating terms for a particular movie in a particular week must be low. And indeed, industry participants note that firms sometimes disagree and retaliation can occur, but it is rare for this to occur. Still, once multiplied by the number of potential occasions for renegotiation, these costs can become sizable and thus parties have incentives to try and keep the frequency of renegotiation low and thus maximize the surplus from the relationship (Masten [1988], Klein [1996]).

Our simple model predicts that renegotiations in favor of the exhibitor will be more often necessary for movies whose box office outcomes, ex ante, is more difficult to predict and for those that perform below expectations ex post. We can test these implications with data on renegotiation that we have for each theater-movie-week for a subset of our contracts, namely 274 of our 430 movies, in 25 theaters, for a total of 2844 theater-movie runs and 8983 theater-movie-week observations. We use a probit model to estimate the relationship between renegotiation, set equal to one if the weekly sharing term for the movie was renegotiated in a given week during the movie run at a given theater, and movie performance and theater characteristics. As we expect observations for a movie in a given theater to be

\footnotetext{
${ }^{15}$ Kenney and Klein [1983] similarly note that, in the context of the diamond industry, the CSO offers a 'warranty' to diamond dealers who purchase their packets by promising that gross classification 'mistakes' will be corrected. We expect that such corrections occur much more often in our context because exhibitors do not earn much rent, while Kenney and Klein suggest that dealers in the diamond industry earn significant amounts of rent.

${ }^{16}$ Filson et al. [2005], in contrast, document some instances of two-sided renegotiations in the U.S. context.
} 
correlated, we cluster errors at the theater-movie level throughout. Results, in the form of marginal effects, are summarized in Table VI.

Testing the implications from the model, however, requires that we measure the predictability of movie revenues as well as whether, in the end, the results meet expectations, on a weekly level. We approach this issue in several different ways.

First, in Table II, columns 3 and 4, we showed that Spanish box office prediction errors are negatively related to U.S. box office revenues. We also noted that industry insiders view the predictability of movies as inversely related to their results in the U.S., with movies that are never released there as those whose results are the least predictable. Given this, in the first three columns of Table VI, we use U.S. Release and U.S. Box Office revenues to measure predictability. We expect renegotiation to be negatively related to both of these such that the frequency of renegotiation is highest for those movies never released in the U.S. and those with low U.S. box office results.

In addition, as mentioned above, we should find more frequent renegotiations of shares for movies that do poorly relative to expectations. In the first three columns of Table VI, we measure deviation from expectations using the error term from our regression in column 2 of Table II. As this variable is equal to zero for movies that were never released in the U.S., its inclusion in our regression amounts to the inclusion of an interaction term between deviation and U.S. release.

Our measures of predictability and of deviation from expectations are at the movie, not the movie-theater-week level. In the first column of Table VI, we address this by showing results for only the first week upon release (column 1) for any theater-movie combination. In columns 2 and 3, we use all weeks of data for each theater-movie, but we introduce a variable that controls for the frequency with which we observe popular movies, namely the interaction of U.S. Box Office results with Weeks since Release for each theater-movie-week observation.

Table VI shows that, whether we focus on just the first week of the movie run, or use all weeks, increased predictability reduces the likelihood of renegotiation. In addition, the frequency of renegotiation is lower for movies that do much better than expected and thus show a high positive deviation from expectations. In other words, results are very consistent with the predictions of our simple model regarding renegotiation. Finally, these results are robust to the inclusion of theater/exhibitor characteristics and demand shifters such as holiday weeks (column 3).

In the last three columns of Table VI, we rely on a different approach to capture the weekly potential for disappointment about the movie's performance. Though we do not observe movie-specific box office results at the weekly level in our data, we have data on theater-level weekly box office results. In these data, we can rely on the fact that movies are shown in 


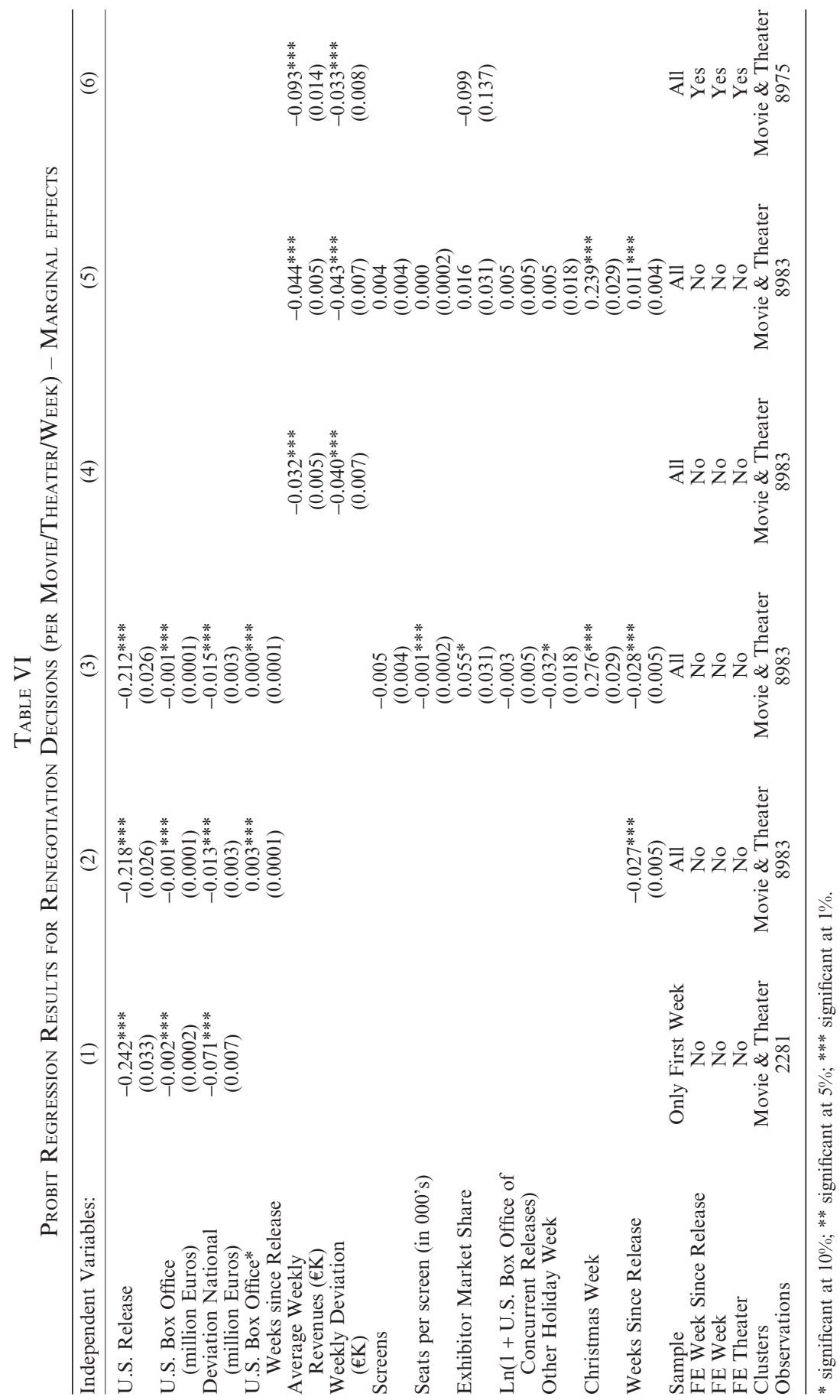


several theaters, and using the technique described in Gil [2004] to attribute shares of box office revenues for each movie at each theater each week. We then calculate the average weekly box office results, which we use as our measure of expected box office outcome, and the difference between a movie's estimated revenues in each theater each week and the above average, which we use as our measure of deviation from expectations.

Results, shown in columns 4 to 6 , confirm again that the frequency of renegotiation is lower for movies that have higher expected revenues, and that renegotiation occurs less frequently when movie results (in a particular week at a particular theater) exceed expectations. In particular, outcomes for movies that exceed expectations by $\$ 1,000$ Euros in any given week are about 4 percentage points less likely to be renegotiated.

The results obtained with either approach also are robust to the inclusion of theater/exhibitor characteristics and other control variables (column 5 or 6). As for the effects of the control variables themselves, we find few significant effects. This is perhaps not surprising given that renegotiation is at the theater-movie-week level while theater characteristics remain constant from week to week for a given movie run. As for the effect of increased movie competition, it is accounted for already in our measure of expected movie revenues in columns 3 and 5 .

\section{IV(iv). Why Not Risk Sharing or Marginal Incentives?}

Some of the features of the distributor/exhibitor relationship and their contractual agreements, and some of the results highlighted above, already imply that risk sharing and marginal incentives are not central concerns in this setting. In this section, we discuss other evidence that leads us to conclude that they are not viable explanations for the use of revenue sharing in the present setting.

First, both exhibitors and distributors are involved in large numbers of transactions. As mentioned earlier, during the 18 months of our data, the average theater showed 111 movies, while the average distributor dealt with 40 theaters for each of its 20 movies. Moreover, the exhibitors whose data we rely on all own several theaters. Both the size of these companies, and the fact that they are all involved in large numbers of transactions, imply important levels of diversification that make it unlikely that risk-sharing, or even the basic insurance/incentive tradeoff emphasized in the agency literature, plays a major role in the present context.

Second, when they are used to resolve either risk sharing or double-sided moral hazard issues, share contracts typically entail lump-sum fees in addition to revenue shares. Under risk sharing, the larger shares of revenues retained by the distributor under high-risk situations - larger shares that are necessary to allocate more risk to this less risk averse party - must be accompanied by a lump-sum fee paid back to the exhibitor for the 
exhibitor's participation constraint to be satisfied (e.g., Stiglitz [1974]). ${ }^{17}$ Similarly, under double-sided moral hazard with no risk aversion, Bhattacharyya and Lafontaine [1995] show that an affine contract implements the first-best, but since the share parameter depends on the desired strength of incentives on both sides, a lump-sum transfer is needed to satisfy the agent's participation constraint (see their appendix). Yet we find no such fees in our data.

Third, the existence of a process by which exhibitors can turn to distributors and request renegotiated shares for those weeks when movies perform below expectations directly contradicts the notion that share contracts are used for risk-sharing purposes. Assuming, as has been typical in this literature, that the exhibitor is the more risk-averse party, and thus the one who should be protected from negative outcomes, the renegotiation option already insures the exhibitors against bad outcomes, making it unlikely that revenue sharing would be needed for that purpose. Moreover, if distributors were to be considered the more risk averse party, they should not be willing to insure exhibitors against bad outcomes as they do, regardless of the fact that revenue sharing might be construed as a mechanism to lower the risk they face under this scenario.

Finally, as mentioned above, the contracts involve systematically decreasing distributor shares with time since release. Yet from a doublesided moral hazard perspective, we find no evidence of a systematic decrease in distributor, and increase in exhibitor, effort required over the weeks that follow the release of a movie to justify this pattern in distributor shares. Consistent with Filson et al. [2005], we see evidence that almost all costs and effort requirements, by distributors and exhibitors, have been expanded or committed to by the time the movie goes into theaters. This led Filson et al. to conclude that sharing plays an insurance role in this context. Instead, we propose that in the face of highly uncertain movie values that differ across locations and over time, revenue sharing does better than fixed weekly rental prices because it allows the compensation of both parties to adjust automatically to ex-post realized values, and thus reduces the need to resort as frequently to renegotiation ex post. Though it by no means eliminates such costs, this form of contracting also has the benefit of reducing the amount of ex-ante haggling - since the number of contract terms is kept low and parties know that payments will automatically adjust to ex-post values.

\section{CONCLUSION}

In this paper we have explained the use of box-office revenue sharing in movie exhibition contracts as a way to devise flexible weekly rental (or

${ }^{17}$ See footnote 7 .

(C) 2012 Blackwell Publishing Ltd and the Editorial Board of The Journal of Industrial Economics 
wholesale) prices for movies. We view the form of the contracts, which are agreed upon before the first week realization of box office results, as a means for distributors to extract most of the downstream surplus in the presence of very uncertain movie values across markets and time. We have shown that this flexible pricing argument captures several important features of these contracts. In particular, we find that distributors retain higher shares for themselves, and that their share goes down more slowly over weeks since release, for movies that are expected to do well in the Spanish market. We also found that distributors get lower shares when dealing with exhibitors with higher market shares of seats in the local market, holding everything else constant, as should happen according to our model (higher $c$, either because of the direct opportunity cost of showing a movie, or equivalently, because of greater exhibitor bargaining power). Finally, we discussed how renegotiated shares are relied upon to compensate exhibitors for below-expectation outcomes in specific weeks. We showed that such renegotiations occur more frequently in cases where movie results are more difficult to predict and when results are below expectations. Both of these data patterns are consistent with the idea that the share contracts represent a formulaic way to set flexible rental prices for the movies, where the contracts are meant to extract basically most or all of the willingness to pay of exhibitors.

We believe that risk-sharing and marginal incentive arguments cannot explain several aspects of the contracting practices in this setting, including the absence of fixed fees and the one-sidedness of the renegotiations that occur in this industry. Without denying the importance of marginal incentive effects in other settings, we expect that our argument that revenue sharing can be a way to achieve flexible pricing applies also in other contexts, including other parts of movie production and distribution, but also in settings such as publisher/author relations, mall leases, franchising and licensing. In fact, Cachon and Larivière's [2005] conclusion that revenue sharing better coordinates the video rental channel, as well as Mortimer's [2008] result that video stores, distributors and consumers do better under revenue sharing, also fundamentally amount to the idea that these contracts lead to 'better' prices between channel members, prices that then lead to the right choices of quantity (here, allocation of limited screen resources to movies).

We hope that our argument, and the evidence supporting it, will help advance not only our understanding of the movie distribution industry, but also of share contracts more generally, beyond the standard risksharing and incentive arguments that are now common in the literature, and that themselves replaced the initial notion that share contracts were by definition inefficient, and simply a reflection of poorly functioning market institutions. 


\section{APPENDIX A}

In what follows, based on the assumptions in the paper, we first derive optimal contract terms for the three types of contracts of interest, and then compare the profitability of the different contracts from the distributor's perspective.

\section{A(i). Box-Office Revenue-Sharing Contracts}

With a contract that specifies the shares of revenues $s_{1}$ and $s_{2}$ that the distributor will receive in each period, the profit function of the distributor is

$$
s_{1} \int_{0}^{v} R_{1} f\left(R_{1}\right) d R_{1}+\operatorname{Pr}\left(\operatorname{Show}_{2}\right) \int_{0}^{E\left(\gamma R_{1} \mid \text { Show }_{2}\right)} s_{2} R_{2} f\left(R_{2}\right) d R_{2}
$$

where Show 2 indicates the movie is shown in period 2. This profit function is subject to the participation constraint of the theater each period, namely

$$
\left(1-s_{1}\right) \int_{0}^{v} R_{1} f\left(R_{1}\right) d R_{1}-\int_{0}^{c} c_{1} f\left(c_{1}\right) d c_{1} \geq k
$$

and

$$
\left(1-s_{2}\right) \int_{0}^{E\left(\gamma R_{1} \mid \text { Show }_{2}\right)} R_{2} f\left(R_{2}\right) d R_{2}-\int_{0}^{c} c_{2} f\left(c_{2}\right) d c_{2} \geq k
$$

In period 2, the theater will show the movie if period 1 revenues are high enough. Specifically, since period 2 revenues are bounded above by $\gamma R_{1}$, the theater will show the movie in period 2 only if its participation constraint is satisfied in expectations. We can solve for the minimum necessary level of $R_{1}$ given $s_{2}$ as

$$
R_{1} \geq \frac{c+2 k}{\left(1-s_{2}\right) \gamma}
$$

Given our distributional assumptions, the distributor's profit maximization problem can now be written as

$$
\max _{s_{1}, s_{2}}\left[s_{1} \frac{v}{2}+\left(1-\frac{c+2 k}{\left(1-s_{2}\right) \gamma v}\right) s_{2} \frac{\gamma}{4}\left(v+\frac{c+2 k}{\left(1-s_{2}\right) \gamma}\right)\right] .
$$

subject to the participation constraints of the theater above.

Note that, with per period shares, the problem is separable. Thus the distributor will set the share for the first week at the level that maximizes his expected revenues subject to the exhibitor's participation constraint. Given that the distributor profits are monotone increasing in $s_{1}$, this constraint is binding such that

$$
s_{1}^{*}=1-\left(\frac{c+2 k}{v}\right) \text {. }
$$


In other words, $s_{1}^{*}$ extracts all expected profits from the movie in period one. Clearly, this optimal share is increasing in $v$, or in movie $i$ expected box office revenues $(=v / 2)$. It is, however, decreasing in $c / 2$, the expected value of alternative movies available at the same time. Finally, it is decreasing in $k$, the operational costs of theater $j$.

(Note that in reality, first-period shares for very promising movies are rarely above $60 \%$. Assuming that alternative movies are such that they generate box office revenues that are perhaps 20 or 30 per cent lower, of which the theater can expect to keep about $50 \%$ as well, then $c$ and even $c+2 k$ assuming $k$ is low enough, could well be somewhat below $.5 v$, leading to an optimal first period share of $60 \%$ according to our solution above.)

For period 2, however, the participation constraint does not bind. Let us call the sharing term that makes the participation constraint in period 2 bind $\overline{s_{2}}$ such that

$$
\overline{s_{2}}=1-\left(\frac{c+2 k}{\gamma v}\right)
$$

If the participation constraint were binding, the probability of showing the movie in period 2 would equal zero and thus expected distributor profits in the second period would also be equal to zero. For that reason, the distributor will choose a share $s_{2}^{*}$ that is lower than $\overline{s_{2}}$. Using the equation for $\overline{s_{2}}$ above, it is easy to show that, since $\gamma<1$ by assumption, $\overline{s_{2}}<s_{1}^{*}$ and therefore $s_{2}^{*}<s_{1}^{*}$.

The solution above involves the distributor choosing a second period share that increases the likelihood that the exhibitor keeps the movie on the screen even when $R_{1}$ is not high. This leads to positive expected profits for the exhibitor ex ante. Substituting the value of $s_{1}^{*}$ in the profit function but leaving $s_{2}$ as is, we get:

$$
\Pi^{s}=\frac{v-c-2 k}{2}+\left(1-\frac{c+2 k}{\left(1-s_{2}\right) \gamma v}\right) s_{2} \frac{\gamma}{4}\left(v+\frac{c+2 k}{\left(1-s_{2}\right) \gamma}\right)
$$

We conclude for now that there exists an $s_{2}^{*}$ that is smaller than $s_{1}^{*}$ that solves this profit maximization problem since $\left.\frac{\partial \Pi^{s}}{\partial s_{2}}\right|_{s_{2}=0}>0$ and $\left.\frac{\partial \Pi^{s}}{\partial s_{2}}\right|_{s_{2}=1}<0$. There is no closedform solution for the optimal $s_{2}^{*}$, however. Taking the F.O.C. of $\Pi^{s}$ with respect to $s_{2}$ we obtain

$$
\frac{\left(1-s_{2}\right)^{3}}{1+s_{2}}-\left(\frac{c+2 k}{\gamma v}\right)^{2}=0
$$

that we can rewrite as

$$
H\left(s_{2}^{*}, v\right)=f\left(s_{2}^{*}\right)-g(v, \gamma)=0 .
$$

Applying the implicit function theorem yields

$$
\frac{d s_{2}^{*}}{d v}=\frac{\frac{d g}{d v}}{\frac{d f}{d s_{2}}}=\frac{-\frac{2}{v}\left(\frac{c+2 k}{\gamma}\right)^{2}}{\frac{-3\left(1-s_{2}\right)^{2}\left(1+s_{2}\right)-\left(1-s_{2}\right)^{3}}{\left(1+s_{2}\right)^{2}}}>0
$$


and

$$
\frac{d s_{2}^{*}}{d \gamma}=\frac{\frac{d g}{d \gamma}}{\frac{d f}{d s_{2}}}=\frac{-\frac{2}{\gamma}\left(\frac{c+2 k}{v}\right)^{2}}{\frac{-3\left(1-s_{2}\right)^{2}\left(1+s_{2}\right)-\left(1-s_{2}\right)^{3}}{\left(1+s_{2}\right)^{2}}}>0 .
$$

Thus the optimal $s_{2}^{*}$ is increasing in movie expected revenues $\frac{v}{2}$ and in $\gamma$, the revenue retention rate from week to week. In addition, we can ascertain how the decrease in share between the two periods, $\Delta s=s_{1}^{*}-s_{2}^{*}$, relates to $v$ and $\gamma$. We get

$$
\frac{d(\Delta s)}{d \gamma}=\frac{d s_{1}^{*}}{d \gamma}-\frac{d s_{2}^{*}}{d \gamma}=-\frac{d s_{2}^{*}}{d \gamma}<0
$$

and

$$
\frac{d(\Delta s)}{d v}=\frac{d s_{1}^{*}}{d v}-\frac{d s_{2}^{*}}{d v} \lesseqgtr 0 .
$$

Since both terms are positive and $s_{2}^{*}$ does not have a closed form solution, the sign of rate of change in sharing terms in relation to $v$ is ambiguous. However, the model implies that the change in shares from period 1 to period 2 will be smaller if $\gamma$, the rate of retention of revenues from week to week, is larger.

\section{A(ii). Fixed Weekly Fees Contracts}

The problem of the distributor who uses a fixed weekly fees contract - where the fixed fees are set at the time of contracting, but are allowed to vary from week to week - is

$$
\max _{T_{1}, T_{2}}\left[T_{1}+\operatorname{Pr}\left(\text { Show }_{2}\right) T_{2}-G\right]
$$

where $G$ represents the higher renegotiation costs associated with fixed prices compared to revenue sharing, subject to the participation constraint of the theater each period.

The probability of showing the movie in the second period depends on the payments from exhibitor to distributor in that period, and on the first period box-office results. Thus we can write the problem above as

$$
\max _{T_{1}, T_{2}}\left[T_{1}+T_{2}\left(1-\frac{\left.c+2 T_{2}+2 k\right)}{\gamma v}\right)-G\right]
$$

subject to

$$
\int_{0}^{v} R_{1} f\left(R_{1}\right) d R_{1}-\int_{0}^{c} c_{1} f\left(c_{1}\right) d c_{1} \geq k+T_{1}
$$

and 


$$
\int_{0}^{\frac{\gamma}{2}\left(v+\frac{c+2 T_{2}+2 k}{\gamma}\right)} R_{2} f\left(R_{2}\right) d R_{2}-\int_{0}^{c} c_{2} f\left(c_{2}\right) d c_{2} \geq k+T_{2} .
$$

Given the objective function of the distributor, which is increasing in $T_{1}$, the participation constraint of the exhibitor in the first period must be binding. The optimal $T_{1}$ thus is

$$
T_{1}^{*}=\frac{v-c}{2}-k
$$

For $T_{2}$, the value that maximizes distributor profit is

$$
T_{2}^{*}=\frac{\gamma v-c-2 k}{4} .
$$

This differs from the value of $T_{2}$ that just satisfies the participation constraint $\left(=\frac{\gamma v-c-2 k}{2}\right)$ because the exhibitor must have incentives to keep the movie on the screen in the second period. Note that $T_{2}^{*}$ is positive and feasible as long as $w-c-2 k>0$. If this condition is not satisfied, the optimal $T_{2}^{*}=0$.

\section{A(iii). Ex-Ante Lump-Sum Fee Contracts}

The distributor's problem under this type of contract is to

$$
\max _{T}[T-G]
$$

where we again use $G$ to represent the higher renegotiation costs associated with fixed fee contracts. Note that one could argue that the cost of renegotiation could be higher or lower under upfront than weekly fees. For one thing, there are more potential terms to be renegotiated under weekly fees. However, there is less at stake each time, so the cost of achieving a compromise for each may be lower. Also, there are circumstances where the movie is not shown in period 2, and this is more likely to occur with weekly than upfront fixed fees. Of course, no renegotiation will be needed in period 2 in those cases. We therefore cannot say a priori which contract leads to higher renegotiation costs. However, it is straightforward to see in the next section that renegotiation costs would have to be much higher under fixed upfront fees than weekly fees to make the latter dominate the former. We do not believe this is the case, and thus for simplicity we assume the same $G$ applies for both types of contracts.

The distributor maximizes its profit subject to the participation constraint of the theater in each period:

$$
\begin{aligned}
& \int_{0}^{v} R_{1} f\left(R_{1}\right) d R_{1}-\int_{0}^{c} c_{1} f\left(c_{1}\right) d c_{1}-k \\
& \quad+\operatorname{Pr}\left(\text { Show }_{2}\right)\left[\int_{0}^{E\left(\gamma R_{1} \mid S h o w_{2}\right)} R_{2} f\left(R_{2}\right) d R_{2}-\int_{0}^{c} c_{2} f\left(c_{2}\right) d c_{2}-k\right] \geq T
\end{aligned}
$$


and

$$
\int_{0}^{\gamma R_{1}} R_{2} f\left(R_{2}\right) d R_{2}-\int_{0}^{c} c_{2} f\left(c_{2}\right) d c_{2} \geq k
$$

We can rewrite this problem as a single period problem

$$
\max _{T}[T-G]
$$

subject to the participation constraint of the theater

$$
\begin{aligned}
& \int_{0}^{v} R_{1} f\left(R_{1}\right) d R_{1}-\int_{0}^{c} c_{1} f\left(c_{1}\right) d c_{1}-k \\
& +\left(1-\frac{c+2 k}{\gamma^{v}}\right)\left[\int_{0}^{\frac{\gamma v+2 k+c}{2}} R_{2} f\left(R_{2}\right) d R_{2}-\int_{0}^{c} c_{2} f\left(c_{2}\right) d c_{2}-k\right] \geq T .
\end{aligned}
$$

Clearly the solution to this problem is such that $T$ makes the overall participation constraint of the theater bind, namely

$$
T^{*}=\left[\frac{v-c-2 k}{2}\right]+\left(1-\frac{c+2 k}{\gamma v}\right)\left[\frac{\gamma v-c-2 k}{4}\right] .
$$

\section{A(iv). Comparing Distributor Profits Across Contract Types}

We can calculate distributor profits for each of the contractual forms above by substituting solutions for $s_{1}, s_{2}, T_{1}, T_{2}$ and $T$ in the corresponding distributor profit function. For simplicity, in this section, we set $k=0$.

For the upfront fixed fee contract, expected distributor profits are

$$
\Pi^{T}=\left[\frac{v-c}{2}\right]+\left(1-\frac{c}{\gamma^{2}}\right)\left[\frac{\gamma v-c}{4}\right]-G .
$$

For the sliding scale of fixed terms $T_{1}$ and $T_{2}$, distributor profits are

$$
\Pi^{T_{1}, T_{2}}=\frac{v-c}{2}+\frac{1}{2 \gamma v}\left(\frac{\gamma v-c}{2}\right)^{2}-G
$$

It is easy to show that $\Pi^{T}>\Pi^{T_{1}, T_{2}}$ and therefore we are left comparing $\Pi^{T}$ and $\Pi^{s}$. (It should be clear from this that the renegotiation costs for the weekly fees contract would have to be much higher than that of the upfront fixed fee contract to overturn the profit advantage of the upfront fixed fee contract.)

We find that profits under revenue sharing contracts are

$$
\Pi^{s}=\frac{v-c}{2}+\left(1-\frac{c}{\left(1-s_{2}\right) \gamma v}\right) s_{2} \frac{\gamma}{4}\left(v+\frac{c}{\left(1-s_{2}\right) \gamma}\right) .
$$


In this case, we only know that the distributor profits are maximized for a value of $s_{2}$ between 0 and 1 since it is easy to show that $\left.\frac{d \Pi^{s}}{d s_{2}}\right|_{s_{2}=0}>0$ and $\left.\frac{d \Pi^{s}}{d s_{2}}\right|_{s_{2}=1}<0$.. Let us set $s_{2}=\frac{1}{2}$ in $\Pi^{s}$ (sharing terms average $50 \%$ in our data). Then comparing distributor profits from revenue sharing to those obtained under an optimally chosen lump-sum payment of $T$ at the beginning of the run, we see that

$$
\Pi^{s}\left(s_{2}=\frac{1}{2}\right)>\Pi^{T}
$$

if

$$
G>\frac{\gamma^{2} v^{2}-4 \gamma v c+6 c^{2}}{8 \gamma v c} .
$$

Thus, for high enough renegotiations costs it is optimal to use revenue sharing contracts rather than upfront (and also weekly, per above) fixed fees.

In sum, although there is no reason to expect that the optimal $s_{2}=\frac{1}{2}$, we have shown that distributor profits can be greater under a revenue sharing contract with $s_{1}^{*}$ and $s_{2}=\frac{1}{2}$ than under the other two forms of contracts. Of course, if we allowed the maximum number of weeks over which the movie can generate positive revenues to be variable, the renegotiation cost advantage of revenue sharing only becomes greater. We conclude that, consistent with industry behavior, revenue sharing can dominate the other two forms of contracts.

\section{APPENDIX B \\ DATA APPENDIX}

We have information on the contracts used in the distribution of 510 movies shown in up to 96 theaters between January 2001 and June 2002. Most of the movies are shown in a subset of the 96 theaters, so the total number of contracts is 13,816. After eliminating contracts for theaters owned by distributors, and a few contracts that are not for first runs, our final sample relates to 430 movies shown in up to 91 theaters in 51 different cities, for a total of 10,167 contracts. The 430 movies were distributed by 22 different distributors. The 91 theaters are owned by seven exhibitors.

The data on movie run length were collected separately, via major Spanish newspapers for theaters operating in Madrid and Catalonia (see Gil [2004]). We only have this information for a subset of our data, namely those movies that were playing in these theaters. We have verified that within the set of 3,706 contracts for which we observe this variable, the descriptive statistics for weeks stipulated are similar to those of our overall sample. Specifically, at the movie/theater (movie) level, the mean weeks stipulated in the set of 3,706 contracts is 5.38 (4.76), with a standard deviation of 3.15 (2.94). For the number of weeks between min and max, these figures are 3.40 (2.76) and 2.10 (1.61) and for the number of weeks at maximum share, they are $1.28(1.19)$ and $0.54(0.41)$ respectively.

Most of the movies in our sample (63\% of them) were released in the U.S. prior to their Spanish release. This includes several non-U.S. movies. In fact, 50 of the 
$63 \%$ are movies produced in the U.S., with the remaining 13\% produced in Asia or the U.K. At the time our data were collected (2001-2002), simultaneous global releases were not as common as they are today. In 2001 the gap between releases in the U.S. and Spain was large enough that Spanish managers could rely on U.S. release information. Of course, Spanish movies are always released first in Spain, except for 'The Others,' a Spanish production starring Nicole Kidman. For other European movies, while they might have been released and become hits in their own countries, those not released in the U.S. prior to their release in other European nations tend to be lower budget and more specialized movies, such that, according to industry members, it is difficult to infer their success in Spain based on outcomes in other European countries.

\section{REFERENCES}

Bhattacharyya, S. and Lafontaine, F., 1995, 'Double-Sided Moral Hazard and the Nature of Share Contracts,' RAND Journal of Economics, 26, pp. 761-781.

Binswanger, H. F. and Rosenzweig, M., 1984, 'Contractual Arrangements, Employment and Wages in Rural Labor Markets: Critical Review,' in Contractual Arrangements, Employment and Wages in Rural Labor Markets in Asia\}, Binswanger, Hans. F. and Mark R. Rosenzweig, eds., (Yale University Press, New Haven, Connecticut, U.S.A.)

Cachon, G. P. and Larivière, M. A., 2005, 'Supply Chain Coordination with RevenueSharing Contracts: Strengths and Limitations,' Management Science, 51, pp. 30-44.

Cheung, S., 1969, The Theory of Share-Tenancy: With Special Application to Asian Agriculture and the First Phase of Taiwan Land Reform, (Chicago University Press, Chicago, Illinols, U.S.A.)

Chisholm, D., 1997, 'Profit-Sharing Versus Fixed-Payment Contracts: Evidence from the Motion Picture Industry,' The Journal of Law, Economics, \& Organization, 13, pp. 169-201.

Dana, J. and Spier, K., 2001, 'Revenue Sharing and Vertical Control in the Video Rental Industry,' Journal of Industrial Economics, 49, pp. 223-245.

Einav, L. and Orbach, B., 2007, 'Uniform Prices for Differentiated Goods: The Case of the Movie-Theater Industry,' International Review of Law and Economics, 27, pp. 129-153.

Eswaran, M. and Kotwal, A., 1985, 'A Theory of Contractual Structure in Agriculture,' American Economic Review, 75, pp. 352-367.

Filson, D.; Switzer, D. and Besocke, P., 2005, 'At the Movies: The Economics of Exhibition Contracts,' Economic Inquiry, 43, pp. 354-369.

Gil, R., 2004, 'Contracting in the Spanish Movie Industry,' Ph.D. dissertation, University of Chicago, Chicago, Illinois, U.S.A.

Hanssen, A. F., 2002, 'Revenue Sharing in Movie Exhibition and the Arrival of Sound,' Economic Inquiry, 40, pp. 380-402.

Ho, K., 2009, 'Insurer-Provider Networks in the Medical Care Market,' American Economic Review, 2009, 99, pp. 393-430.

Holmstrom, B., 1979, 'Moral Hazard and Observability,' Bell Journal of Economics, 10, pp. 74-91.

Ioannou, I.; Mortimer, J. and Mortimer, R., 2011, 'The Effects of Capacity on Sales under Alternative Vertical Contracts,' Journal of Industrial Economics, 59, pp. 117 154.

Kenney, R. and Klein, B., 1983, 'The Economics of Block Booking,' Journal of Law and Economics, 26, pp. 497-540. 
Klein, B., 1996, 'Why Hold-Ups Occur: The Self-Enforcing Range of Contractual Relationships,' Economic Inquiry, 34, pp. 444-63.

Lafontaine, F. and Masten, S. E., 2002, 'Contracting in the Absence of Specific Investments and Moral Hazard: Understanding Carrier-Driver Relations in the U.S. Trucking', NBER working paper \# 8859 (National Bureau of Economic Research, Inc., 1050 Massachusetts Avenue, Cambridge, Massachusetts U.S.A.).

Masten, S., 1988, 'Equity, Opportunism and the Design of Contractual Relations,' Journal of Institutional and Theoretical Economics, 144, pp. 180-195.

Mortimer, J., 2008, 'Vertical Contracts in the Video Rental Industry,' The Review of Economic Studies, 75, pp. 165-199.

Oyer, P., 2004, 'Why Do Firms Use Incentives that Have No Incentive Effects?' The Journal of Finance, 59, pp. 1619-1649.

Reid, J., 1976, 'Sharecropping and Agricultural Uncertainty,' Economic Development and Cultural Change,' 24, pp. 549-576.

Rubin, P., 1978, 'The Theory of the Firm and the Structure of the Franchise Contract,' Journal of Law and Economics, 21, pp. 223-233.

Slade, M. E., 1996, 'Multitask Agency and Organizational Form: An Empirical Exploration,' International Economic Review, 37, pp. 465-486.

Stiglitz, J., 1974, 'Incentives and Risk Sharing in Sharecropping,' The Review of Economic Studies, vol. 41, pp. 219-255.

Svejnar, J., 1986, 'Bargaining Power, Fear of Disagreement and Wage Settlements: Theory and Evidence from U.S. Industry,' Econometrica, 54, pp. 1055-1078.

Vogel, H., 2001, Entertainment Industry Economics, $5^{\text {th }}$ edition, (Cambridge University Press, Cambridge, England).

Weinstein, M., 1998, 'Profit-Sharing Contracts in Hollywood: Evolution and Analysis,' Journal of Legal Studies, 27, pp. 67-112. 